\title{
FORMAÇÃO PROFISSIONAL E CRISTÃ DA JUVENTUDE SALESIANA E A PEDAGOGIA DE DOM BOSCO
}

\author{
LA FORMACIÓN PROFESIONAL Y CRISTIANA DE LA JUVENTUD \\ SALESIANA Y LA PEDAGOGÍA DE DON BOSCO
}

\section{PROFESSIONAL QUALIFICATION AND YOUTH CHRISTIAN AND SALESIAN PEDAGOGY OF DON BOSCO}

\author{
Núbia Ferreira ALMEIDA ${ }^{1}$
}

RESUMO: O artigo relata os passos iniciais de uma pesquisa sobre História da Educação Salesiana e o desenvolvimento da Pedagogia de Dom Bosco em escolas profissionais, especificando a pesquisa realizada nos arquivos das escolas profissionais salesianas localizadas em Juazeiro do Norte (Brasil) e a Oficina de Arte e Ofício de São Jose em Lisboa (Portugal) inauguradas, respectivamente, em 1906 e 1942. A investigação visa analisar como os diferentes atores sociais, vivenciando realidades específicas, se apropriam do saber educacional dos salesianos para produzir suas histórias educacionais constatando abrangências e limitações comuns em seus diferenciados contextos. Os documentos e outras fontes que serviram de divulgação do modelo educacional institucionalizado correspondiam ao que determinado grupo esperava de uma instituição escolar e que está expresso na forma como se desenvolveu a experiência portuguesa e brasileira por meio do uso da pedagogia de Dom Bosco. Utilizamos concepções teóricas sobre o que diz respeito ao desenvolvimento da escolarização, a partir das práticas escolares cotidianas nas oficinas. Processo que no entender dos autores Jean Michel Chapolie e Jean Michel Briand constitui resultado de uma interação da Instituição com a sociedade local, onde podemos observar o entrecruzamento de interesses sociais, morais e religiosos que definem uma determinada população.

PALAVRAS-CHAVE: Educação Salesiana. Formação Profissional e Cristã.

RESUMEN: El artículo da cuenta de los pasos iniciales de una investigación sobre la historia de la educación salesiana y el desarrollo de la pedagogía de Don Bosco en las escuelas profesionales, especificando la investigación llevada a cabo en los archivos de las escuelas profesionales salesianas de Juazeiro do Norte (Brasil) y Taller de Arte y la oficina de San José, en Lisboa (Portugal), respectivamente, se abrió en 1906 y 1942. la investigación pretende analizar cómo los diferentes actores sociales, experimentando realidades específicas, apropiarse del conocimiento de la educación de los Salesianos para realizar sus historias educativos señalando los alcances y limitaciones comunes en sus diferentes contextos. Documentos y otras fuentes que sirvieron para dar a conocer el modelo educativo institucionalizado correspondian a ese grupo en particular se espera de una institución escolar y que se expresa en la forma desarrollada de la experiencia portuguesa y brasileña a través del uso de la pedagogía de Don Bosco. Utilizamos las concepciones teóricas de lo que se refiere al desarrollo de la educación, de las prácticas escolares cotidianas en los talleres. Proceso que en opinión de los autores Jean Michel Chapolie y Jean Michel Briand es el resultado de la interacción de

1 Pós-dourada em Educação pelo Instituto de Educação da Universidade de Lisboa e Doutora em Educação Brasileira. Professora do Departamento de Ciências Sociais da Universidade Regional do Cariri (URCA). 
la institución con la sociedad local en el que podemos observar la intersección de social, moral y religiosa que definen una población dada.

PALAVRAS CHAVE: La educación salesiana; la formación profesional y Christian.

ABSTRACT: This article show us the inicial stages of a research about the Salesian Education History and the development of Don Bosco's pedagogy in vocational schools, specifying the research conducted in the archives of the Salesian professional schools in Juazeiro do Norte (Brazil) and Art Workshop and Craft of San Jose in Lisbon (Portugal) opened respectively in 1906 and 1942. The research seeks to analyze how different social actors, experiencing specific realities, appropriating the educational knowledge of the Salesians to make their educational stories noting scopes and limitations common in their different contexts. The Documents and other sources that served to publicize the institutionalized educational model corresponded to that particular group expected from a school institution and that is expressed in the way developed the Portuguese and Brazilian experience through the use of Don Bosco's pedagogy. We use theoretical conceptions of what concerns the development of education, from the everyday school practices in the workshops. Process which in the opinion of the authors Jean Michel Chapolie and Jean Michel Briand is a result of the institution's interaction with the local society where we can observe the intersection of social, moral and religious that define a specific population.

KEYWORDS: Professional qualification. Salesian Education and Christian.

\section{Introdução}

$\mathrm{O}$ artigo relata os passos iniciais de uma pesquisa sobre História da Educação Salesiana e o desenvolvimento da Pedagogia de Dom Bosco em escolas profissionais, especificando a pesquisa realizada nos arquivos das escolas profissionais salesianas localizadas em Juazeiro do Norte (Brasil) e a Oficina de Arte e Ofício de São Jose em Lisboa (Portugal) inauguradas, respectivamente, em 1906 e 1942. A investigação visa analisar como os diferentes atores sociais, vivenciando realidades específicas, se apropriam do saber educacional dos salesianos para produzir suas histórias educacionais constatando abrangências e limitações comuns em seus diferenciados contextos. Os documentos e outras fontes que serviram de divulgação do modelo educacional institucionalizado correspondiam ao que determinado grupo esperava de uma instituição escolar e que está expresso na forma como se desenvolveu a experiência portuguesa e brasileira por meio do uso da pedagogia de Dom Bosco. Utilizamos concepções teóricas sobre o que diz respeito ao desenvolvimento da escolarização, a partir das práticas escolares cotidianas nas oficinas. Processo que no entender dos autores Jean 
MichelChapolie e Jean Michel Briand(1994) constitui resultado de uma interação da Instituição com a sociedade local, onde podemos observar o entrecruzamento de interesses sociais, morais e religiosos que definem uma determinada população.

Após a independência brasileira, era necessário recriar estruturas de províncias, interiorizando as instâncias políticas de cada região e simultaneamente, refazendo ligações com o nacional, para tanto, há uma acirrada luta entre posicionamentos ideológicos contraditórios para formar o sistema educacional brasileiro. Portugal vivencia um processo de renovação do ensino e de circulação de modelos educacionais, mostrando semelhanças entre os países citados em torno do tema educação, estavam em jogo, questões relacionadas à política de educação popular e a organização pedagógica para a escola primária. As organizações de instituições profissionalizantes de caráter assistencialista, faziam-se presente nestes cenários políticos de transformações sociais. Em compensação o início do século XX, especificamente, entre os anos de 1920 e 1940 observamos, também, o surgimento de novas ideias em relação a educação profissionalizante, para atender as novas expectativas de uma sociedade em franca transformação.

A escola passou a ser considerada como fator de modernização e mudança social. Fazia-se necessária uma escola nova para a formação do homem novo para uma nova sociedade que se delineia, mudando o perfil das cidades e das famílias, articulando-se com as exigências do desenvolvimento industrial e o processo de urbanização. O cenário educacional configurado a partir da segunda metade do século XIX apresenta uma semelhança do processo histórico que exigia a escolarização em massa, mesmo considerando as particularidades locais, torna-se um fenômeno globalizado que exigia a obrigação escolar, a responsabilidade estatal pelo ensino público, a secularização do ensino e a secularização da moral, a nação e a pátria como princípios norteadores da cultura escolar e a educação popular. (ANJOS, 1999).

O trabalho pastoral e educativo da obra salesiana ganha novos olhares e readaptações na medida em que se instalam em diversos lugares pelo mundo. Neste sentido, o Século XX foi um marco na história da Congregação. Observamos que em cada contexto histórico há adaptações para adequação de suas ações ao público a que se destina, porém, os enunciados da Pedagogia de Dom Bosco, fundador desta obra, é o exemplo a ser seguido, direcionando todo o processo educativa institucional. Dom Bosco acolheu os jovens do seu tempo, abrigou-os em casas e oratórios para que pudesse educá-los no cristianismo, salva-los dos perigos da juventude, orienta-los a 
tornarem-se "bons cristão e honestos cidadãos", por meio de uma educação institucional, específica, tendo como base a prevenção e a escolarização.

\section{Espiritualidade e Pedagogia de Dom Bosco}

A Congregação Salesiana de Dom Bosco foi fundada em Turim, Itália, em 1874. O criador dessa obra chama-se Giovani Melquior Bosco. Nasceu em 16 de agosto de 1815, no lugarejo de Benchi, distante 20 quilômetros da cidade de Chieri, no município de Castelnuovo d'Asti. Dom Bosco, como é conhecido, e um grupo de sacerdotes e irmãos decidiram fundar uma família com regras definidas, direcionadas às atividades paroquiais, apostolado, prática de caridade cristã e ensino, inspirados na vida de São Francisco de Sales $^{2}$ (1565-1622), daí o nome de Salesiansos (Sales).

Os princípios educacionais salesianos encontram-se no Regulamento Geral em seu capítulo VIII, que informa os meios pelos quais se valem os salesianos para efetuar a formação destinada à missão dos educadores-pastores, falando sobre formação intelectual quando esclarece que a organização dos estudos: “[...] harmonize as exigências da seriedade científica com as da dimensão religioso-apostólica do nosso projeto de vida" ${ }^{3}$.

Verificamos que Dom Bosco não era alheio aos problemas do seu tempo, as suas ações passaram, ao longo dos anos, por diversas modificações, para atender às demandas de novas realidades. Direcionava seu trabalho para o desenvolvimento de uma educação institucional. Tirava o jovem da rua e levava para uma instituição: oratório, pensionato, internato, escola, etc. Instituição significava, para ele, um grupo humano, feito de pessoas vivas que se relacionam de formas diversas. "Por que se quer substituir ao amor a frieza de um regulamento?", pergunta ele na sua Carta de Roma uma carta dirigida aos salesianos, considerada um dos escritos pedagógicos de Dom Bosco, na qual procurava traçar o perfil ideal do Oratório Festivo por ele criado ${ }^{4}$.

${ }^{2}$ São Francisco de Sales nasceu na França em 1565. Estudou em Paris e em Pádua, na Itália. Tornou-se líder da Contrarreforma, falecendo em Lyon, na França, em 1622.

${ }^{3}$ Regulamento Geral in CONSTITUIÇÕES SALESIANAS, cap. VIII, art. 82, p. 160, 1984.

${ }^{4}$ De acordo com a Inspetoria Salesiana do Nordeste: Os Oratórios Festivos salesianos são espaços socioeducativos abertos ao convívio e formação humana. Envolve a comunidade local no trabalho voluntário e na animação dos grupos infanto-juvenis. Constituem-se como um espaço para prática de esporte, brincadeiras, atividades sócio pedagógicas favorecendo assim, o intercâmbio, sobretudo cultural e social. 
É oportuno lembrar que o Oratório Festivo, sendo marca principal do trabalho de Dom Bosco, teve influência da espiritualidade de São Francisco de Sales, visto que, desde os séculos VX e XVI, já se tinha indícios, na Itália, dessa experiência pedagógica, portanto, Vitorino da Feltre foi a influência laica no período da renascença. Ele fundou uma obra chamada Casa Giocosa (mansão da alegria). Trata-se de um leigo que viveu na cidade de Pádua no século XV, que em sua casa atendia aos jovens do gênero masculino e feminino mais carentes, proporcionando-lhes formação moral e intelectual. Sua ação educativa era envolvida por seus ideais humanistas e cristão e já utilizava jogos para atrair esses jovens.

A influência religiosa recebida por Dom Bosco vem do padre Filipe Neri (15151595). Filipe Rômulo Neri nasceu num bairro popular de Florença, em 1515, e viveu em Roma no século XVI, em um contexto sociopolítico conturbado em que muitos jovens e adolescentes passavam enorme necessidade. Filipe Neri criou um ambiente educativo alegre para ajudar, tanto material como espiritualmente, todos esses jovens.

Segundo Braido (2008), Dom Bosco recebeu, desses educadores, influência cultural e religiosa e, assim, começou a desenvolver o Oratório Festivo, na cidade de Turim, com a intenção de interferir na realidade social da juventude pobre daquela cidade.

O trabalho por ele desenvolvido entre os jovens era especial por suas características específicas: a casa que acolhia, a Igreja, onde o jovem podia rezar, e o pátio, onde ele brincava com seus colegas. Graças a essas práticas, os seus sucessores salesianos começaram a difundir essa atividade em todo o mundo até chegar ao Brasil em 1883, por intermédio de negociações da Igreja Católica com o Império Brasileiro (AZZI, 1982),

Apresentar uma interpretação da ação educacional de Dom Bosco remonta aos cuidados sobre a utilização da literatura pertinente que nos faz lembrar Certeau (1982), quando as histórias de vida de padres fazem evocar o discurso de um antigo gênero literário chamado de hagiografia, que estuda os atores do sagrado, os santos, e visa à edificação. É uma história que se refere àquilo que é essencialmente exemplar:

[...] Mas o documento hagiográfico se caracteriza também por uma organização textual na qual se desdobram as possibilidades implicadas pelo título outrora dado a este tipo de relato. Acta, ou mais tarde, Acta sanctorum. [...] Cada vida de santo deve ser antes considerada como um sistema que organiza uma manifestação graças à combinação topológica de 'virtudes' e de 'milagres'. (CERTEAU, 1982, p. 242-243). 
Admitimos a necessária leitura desse tipo de documento, porém, procuramos fazer uso crítico de seu conteúdo. Rodriguéz (2003) e Schièlé (2008), nos relatos a seguir, mostram a maneira como se deu a aproximação de Dom Bosco e o seu encaminhamento para a vida religiosa. No ano de 1829, com 13 anos, participou de uma pregação na Paróquia de Buttigliera. O capelão de Murialdo, paróquia a que Bencchi pertencia, perguntou a João se ele se lembrava de alguma coisa sobre o sermão e João o surpreendeu, ao repetir-lhe o sermão inteiro. Este capelão percebeu a sua vocação e tornou-se, assim, um pai, mestre e benfeitor. O padre João Calosso, de Chieri, capelão de Murialdo, faleceu em 1830. Teve influência, também, de Comollo ${ }^{5}$, modelo de virtude, como deduz das "memórias do oratório", e do padre José Cafasso ${ }^{6}$. Mudou em 1831, para Chieri, João criou, junto com seus amigos, a "SOCIEDADE DA ALEGRIA": nada de palavras ou atos que pudessem envergonhar um cristão, fidelidade aos deveres escolares e religiosos e alegria em todas as situações. Em 1834 procurou o Convento da Paz, dos franciscanos, em Chieri. Optou, porém, pelo Seminário Diocesano, onde passou sete anos. Não gostava do distanciamento que existia entre os padres e os seminaristas, isso o desagradava e, ao mesmo tempo, dava-lhe ânimo para tornar-se padre e mudar esse costume.

De acordo com Brocardo (2005) e Rodriguéz (2003), possuía inquietação intelectual, "Nem a Filosofia, nem a Teologia especulativa preenchiam as horas de estudo do seminarista Bosco. Ele preferia as Ciências Religiosas positivas, muito pouco cultivadas nos seminários da época". Ele era agitado, nas férias de volta a Benchi trabalhava no campo e reunia os jovens para fazer excussões. No dia 6 de julho de 1841, o diácono Bosco recebeu o Sacerdócio na Capela do Arcebispo de Turim. A partir de então, passou a ser chamado de Dom Bosco.

Dom Bosco desenvolveu um sistema pedagógico considerado inovador e conseguiu reunir em torno de si um prodigioso movimento de apostolado. São Francisco de Sales, doutor da Igreja Católica, deu origem a uma escola de espiritualidade que normalmente é reconhecida como "Espiritualidade Salesiana”.

${ }^{5}$ Luis Comollo nasceu na aldeia de Para, Cinzano, província de Turim, em abril de 1817, e faleceu em Chieri em abril de 1839. Foi nomeado reitor e formador de novos sacerdotes no Seminário Diocesano de Chieri, Arquidiocese de Turim, e lá conheceu João Bosco.

${ }^{6}$ José Cafasso nasceu em Castelnuovo d'Asti, em 1811, e faleceu em 1860. Foi canonizado em 1947. Desenvolveu suas atividades como moralista, confessor, formador de sacerdotes e de leigos. Sugeriu como modelo a imitar São Francisco de Sales e São Felipe Néri. Dom Bosco foi um dos vocacionados por ele. 
Nas Constituições Salesianas ${ }^{7}$, Cap. I, artigo 3, encontramos elementos para entender a natureza e missão dessa sociedade, bem como a sua consagração apostólica:

Com a profissão religiosa oferecemo-nos a nós mesmos a Deus para caminhar no seguimento de Cristo e trabalhar com Ele na construção do Reino. Missão apostólica, comunidade fraterna e prática dos conselhos evangélicos são os elementos inseparáveis da nossa consagração, vividos num único movimento de caridade para com Deus e com os irmãos (CONSTITUIÇÕES SALESIANAS, Cap. I, artigo 3).

Segundo Brocardo (2005), Dom Bosco deve ser observado desde a memória e profecia, porque representa aquilo que Deus quer: "santo do passado e profecia viva", ou seja, partir de uma abordagem histórica e profética. $\mathrm{O}$ autor considera que, assim, é possível ressuscitar a história sem deformá-la, dentro dessa perspectiva:

\begin{abstract}
A aproximação de D. Bosco deve desembocar no conhecimento de 'D. Bosco total', tal como o forjaram seus 72 anos de vida e o trabalho intenso como realizou sobre si mesmo. Compreender-se-á então como ele se nutriu da teologia da espiritualidade de seu tempo, como participou da consciência que a igreja tinha de si, sob o pontificado de Pio IX, e como determinadas disposições suas são reflexo da formação eclesiástica recebida no tempo da Restauração. (BROCARDO, 2005, p. 16).
\end{abstract}

Pela perspectiva profética, Brocardo (2005) adverte para o fato de que esta é uma forma de encontrar o seu significado e, também, de ser fiel ao "Deus da história", pois a perspectiva profética é portadora de futuro, de valores insuperáveis e perenes:

A igreja sempre se apropriou de quanto há de bem na vida dos povos-, relançados como profecia em nossa cultura. Afirmou Paulo VI: 'Os princípios humanos e cristãos nos quais se baseia a sabedoria de Dom Bosco carregam em si valores que não envelhecem', pois 'esse incomparável exemplo de humanismo pedagógico [...] está enraizado no evangelho'. (BROCARDO, 2005, p. 16-17).

A elaboração de um pensamento sobre Dom Bosco tem relação com a forma como ele fundamentou a sua concepção teológica e pedagógica, fato considerado importante para entender a sua ação pedagógica. Na literatura, mostra-se de duas formas que, certamente, leva esse texto a momentos distintos de elaboração teórica quando nos referimos ao padre santo educador refletido em autores que tendem, como esclarece Aubry (s/d), a preservar uma tradição heroica, maravilhosa, e outros que levam essa tradição ao estudo mais apurado e crítico da ciência, colocando-o num lugar mais

${ }^{7}$ Constituição Salesiana é o código fundamental de todo salesiano, sua identidade. O manual utilizado nesta pesquisa é um trabalho repensado e reelaborado segundo exigências do Concílio Vaticano II. Foi promulgado pelo reitor-mor em 8 de dezembro de 1984. Contém o Estatuto dos Regulamentos Gerais e alguns escritos de Dom Bosco. 
humano do que santo, mediante um estudo criticamente fundamentado, afastando-o do sobrenatural. O texto ora elaborado segue orientação das duas tendências consideradas importantes elementos do pensamento sobre a fundamentação do trabalho educativo de Dom Bosco, e utilizamos, largamente, as Constituições e Regulamentos da Sociedade de São Francisco de Sales (1984), mais conhecida como Constituições Salesianas.

\section{Escola Profissional Salesiana no Brasil e Portugal}

Os salesianos mostraram ao longo da sua história uma inestimável contribuição em diversos países do mundo, levando a sua cultura, a sua forma especial de educar, por meio do "Sistema Preventivo" e assim, vão colaborando com o processo de cristianização da Igreja Católica. No Brasil chegam em 1883, na Baía de Guanabara. Representado pelos padres, Luis Lasanga, Miguel Borghino, Carlos Peretto, Domingos Delpiano. O país estava marcado pelo período de industrialização, anticlericalismo, êxodo rural, escravidão e problemas de saúde que afetavam a população. Neste contexto esses padres começam um trabalho de assistência à juventude pobre. Em Portugal temos a importante contribuição do Padre Filipe Rinaldi, inspetor dos Salesianos na Península Ibérica. Na ocasião visitara as instalações do Colégio dos Órfãos de São Caetano. Tratava-se de um Colégio com uma longa tradição histórica, fundado no Século XVIII pelo Arcebispo de Braga, frei Caetano Brandão. Sob a designação de "Seminário dos meninos". De acordo com Amador Anjos (1999) em seu livro: "Nos primórdios da Obra Salesiana em Portugal", a implantação da obra de Dom Bosco inicia na cidade de Braga (1894), depois irão para Lisboa (1896) e chega ao Porto em 1909.

Neste período há, também, uma intensa troca de cartas entre os padres Salesianos e o Padre Cícero Romão Batista, fundador da cidade, de Juazeiro do Norte, lugar onde estes padres vão protagonizar importante história em favor da juventude pobre, por meio de um Colégio e de escolas profissionalizantes e de "Oratórios Festivos".

Semelhante ao trabalho realizado no Brasil, havia aulas de instrução primária, música e instrumental. As oficinas profissionais ensinavam ofícios de alfaiataria, sapataria, marcenaria e fabricação de relógio e sino. Entre outras ações educacionais que foram se expandido ao longo da história. As ações educacionais eram assistidas pela 
preocupação de introduzir a devoção a Nossa Senhora Auxiliadora e o Coração de Jesus.

Os elementos pedagógicos da educação salesiana podem ser observados por meio do incentivo aos estudos, à boa conduta dos alunos, o relacionamento próximo com as famílias, quadros de honra, certames catequéticos, diploma de exame no fim do curso, pequena remuneração para os aprendizes das oficinas, o clima de família, laços de confiança entre educadores e educandos.

Todo o programa acentuava a preocupação contínua em incutir a consciência do dever, consistindo principalmente em promovê-los, instruindo-os e capacitando-os profissionalmente para os tornar operários competentes e úteis à sociedade. Especificamente em Juazeiro do Norte, os salesianos conseguiram reconhecimento de toda a sociedade local pelo trabalho educacional realizado. Em Lisboa tem o reconhecimento do governo português pela educação de qualidade proporcionada a centenas de operários, alcançando grande projeção social.

As escolas profissionais, aquelas destinadas a ensinar as artes e ofícios manuais, representam um forte aliado do trabalho de cristianização da Igreja católica. Oportunidade em que a pedagogia de Dom Bosco utiliza o preceito religioso: "Trabalho e Oração". Esta preocupação com o ensino profissionalizante em Juazeiro do Norte, vinha do padre Cícero que, superando a ideia, vigente em sua época, que considerava desonroso o trabalho manual e dava ênfase à educação literária e retórica das elites, de forma diferente, via no aprendizado profissional uma esperança para as famílias pobres alcançarem ascensão social com a formação de seus filhos aos serem transformados em peritos em uma arte ou ofício.

De acordo com o Almanaque do Cariri (1949), a escola profissional salesiana em Juazeiro ofertava cursos de marcenaria, fundição e mecânica geral e a fabricação de relógios. A marcenaria estava em pleno funcionamento, tendo como um dos funcionários o mestre Joaquim Salustiano, que faleceu no dia 24 de fevereiro de 1942. Foi em 26 de fevereiro de 1944, sob a direção do padre Luiz Mendonça, que se iniciou o "prolongamento" da oficina de mecânica e marcenaria para a sede da futura oficina de alfaiate e sapateiro.

Desta forma, os salesianos cumpriram, de início, a missão que também lhes fora atribuída pelo padre Cícero, por meio do testamento, bem como a assistência às crianças pobres, pois, em diversos momentos dessa história, apareceram os oratorianos, sejam em missas, comemorações na cidade, nas brincadeiras com os padres. Expresso na 
Crônica da Casa, com um momento em que se reúnem muita gente e muita alegria. Não era somente com o trabalho que os alunos menos abastados ocupavam seu tempo. Os estudantes das escolas profissionalizantes poderiam participar de um curso noturno, ofertado pelos padres, aos adultos, com a intenção de reduzir o analfabetismo.

Entre os encarregados das oficinas, destacamos, também, o Senhor Pedro Mielle. Ele era paulista, estudou no Colégio Santa Rosa em Niterói, Estado do Rio de Janeiro. A interação com os diversos segmentos da sociedade se faz presente nas duas realidades investigadas, ambos os países, deixam transparecer uma cordial colaboração com o trabalho dos padres desde a sua chegada, conforme constatamos na literatura sobre o tema.

Em meio aos problemas de instalação das obras, os padres dão prosseguimento aos trabalhos de sua pastoral, ocupando o espaço social e político correspondente ao que foi traçado, pelo processo de Romanização da Igreja católica em seu projeto de cristianização. A cultura salesiana se fez presente na cultura destes países, por meio das escolas profissionalizantes, dos cânticos dos oratorianos, que se exibiam para a sociedade por meio das festas em homenagem ao Rei dos Reis, e também o culto a Maria Auxiliadora.

Em Lisboa destacamos as oficinas de São José com a sua importante contribuição social e educativa. Se instalam em Portugal com o intuito de amenizar problemas sociais que acometiam os jovens mais necessitados. Acolhia alunos em regime de internato. Os alunos aprendiam uma arte ou ofício e tinha educação formal somente das séries iniciais. Da mesma forma que acontecia em outros países, eles não deixavam de dar atenção aos Oratorianos, aos domingos e feriados. Favorecendo os outros jovens da comunidade que viviam num ambiente socialmente desfavorecido para a educação.

Conforme apresenta Amador Anjos (1999) as Oficinas de São José em Lisboa, encampado pela Congregação Salesiana, fez um trabalho inspirado nas outras instituições que já existiam desde os anos de 1890 do século XIX. O autor ainda diz que o ideal de educação de Dom Bosco era compartilhado pelo padre Francisco Herculano Cordeiro e Dona Maria Izabel de Lacerda Castelo Branco, ambos estavam preocupados com questões relacionadas ao analfabetismo e em amenizar os problemas das crianças de rua. Eles preparam o ambiente para a instalação das Oficinas em 1990. Mas, somente quatro anos mais tarde, devido a problemas financeiros inicia o trabalho das oficinas, de marcenaria e a sapataria e, mais tarde a alfaiataria. 
A chegada dos Salesianos em Lisboa é, também, de iniciativa de personagens da sociedade local, por meio de cartas enviadas ao padre Michele Rua, reivindicam o envio de alguns salesianos para tomarem conta da "Associação Protectora do Colégio do Sagrado Coração de Jesus”. Foi assim que o Padre Miguel Rua, em Janeiro de 1894, encarrega o provincial de Espanha, Padre Filipe Rinaldi, de visitar as obras que em Portugal esperavam a intervenção dos Salesianos para dar respostas aos problemas sociais que lhes apresentavam, bem como, frente aos problemas financeiros que impediam o funcionamento pleno das oficinas, pois o número de alunos aumentou de 3 em 1890, para 43 em 1893.

O trabalho promissor das oficinas faz surgir a necessidade de ampliar as instalações físicas da escola e um novo prédio foi construído. Em 1905, mudaram-se para o novo edifício, cuja inauguração solene data de 19 de março de 1906. O reconhecimento deste trabalho, pela população local pode ser observada quando o Jornal “O Século", citado por Martins (1941) divulga o seguinte:

\footnotetext{
Mostrámos como a mais perfeita bondade Evangélica, associada à mais adiantada pedagogia, convertia essa instituição num dos engenhos mais formidáveis até hoje inventados pela virtude e pela caridade contra o vício, o crime e a desgraça (...) E diante dessas aulas claras, dessas oficinas maravilhosamente instaladas (...) dos motivos artísticos e sentimentais que por toda a parte solicitam a mente para um convívio alto e nobre. (MARTINS, 1942, p. 9)
}

Amador dos Anjos faz referência a um diploma de "Benemerência no campo da educação e do ensino" conferido às Oficinas de São José, por ocasião do Congresso Pedagógico de Lisboa em 1908. Da mesma forma, em 1939, pelo Presidente da República, Marechal Carmona, com a comenda da Instrução Pública e pelo Ministério da Educação.

A educação ofertada pelos salesianos por meio de suas obras educativas e sociais, mesmo em diferentes países apresentam o mesmo objetivo que é levar a educação cristã e a promoção social de jovens sem recursos, valorizando a educação profissionalizante em escolas de arte e de ofícios. Portanto, estas são apenas reflexões introdutórias sobre a educação salesiana ofertada a estes jovens dos países citados e constituem parte inicial de uma pesquisa em andamento. 


\section{Conclusões}

Estudar o papel da pedagogia de Dom Bosco nestes cenários políticos, sociais e educacionais permitem visualizar um projeto educativo mais abrangente no sentido de encampar as exigências dos novos tempos e, também, exigências educacionais que abrangem os jovens das camadas sociais menos privilegiadas.

Percebemos que contextos históricos e culturais marcam o encontro entre estas duas distintas Nações. Referimo-nos aos descompassos do sistema educacional Brasileiro e Português que configuram momentos em que as teorias pedagógicas não se aplicavam na prática das instituições educativas. As bases ideológicas que organizavam a política educacional não condiziam com a realidade. Da mesma forma o Brasil passa por momentos de fragilidade na organização do seu sistema educacional, também, por razões sociais, políticas, ideológicas.

As escolas profissionais, aquelas destinadas a ensinar artes e ofícios manuais, representam, mais que ensinar uma arte ou ofício para resolver problemas sociais e econômicos dos jovens desamparados, constitui, também, um forte aliado do trabalho de cristianização da Igreja católica. Cidadania e catolicismo são complementares e indispensáveis na educação da juventude. O bom cidadão seria aquele que honraria sua pátria e propagaria a fé católica, contribuiria para a manutenção da ordem, e seria, também, um trabalhador útil à sociedade. Com notáveis semelhanças no que se refere a forma de ofertar educação e da aceitação da população quando nos referimos ao apoio social recebido nestes países aos quais nos referimos.

\section{REFERÊNCIAS}

ANJOS, A. Oficinas de S. José, os Salesianos em Lisboa. Lisboa: Edição Salesiana, 1999.

AUBRY, J. (coord). Escritos espirituais de São João Bosco. Trad. Fausto Santa Catarina. Roma: n/d. São Paulo: Escolas Profissionais Salesianas.

AZZI, R. Os salesianos no Brasil à luz da história. São Paulo: Dom Bosco, 1982.

BOGDAN, R.; BIKLEN, S. Investigação qualitativa em Educação: fundamentos, métodos e técnicas. In: Investigação qualitativa em educação. Portugal: Porto Editora, 
1994.

BROCARDO, P. Dom Bosco: profundamente homem, profundamente santo. Trad. Yvone Maria de Campos Teixeira da Silva. 2. ed. São Paulo: Editora Salesiana, 2005.

CHATIER, R. A história cultural: entre práticas e representações. (Trad. Maria Manuela Galhardo). 2. ed. Portugal: DIFEL, 1998.

CERTEAU, M. A escrita da história. Trad. Maria de Lourdes Menezes. Rio de Janeiro: Forense Universitária, 1982.

CONSTITUIÇÕES E REGULAMENTOS. Constituições e regulamentos da Sociedade de São Franciso de Sales. Mooóca, SP: Escolas Profissionais Salesianas, 1884.

CHAPOULIE, J.; BRIAND, J. A instituição escolar e a escolarização: uma visão de conjunto. Educação \&Sociedade, São Paulo, n. 47, abril, 1994.

GARCIA, S. R. O. "O fio da história: a gênese da formação profissional no Brasil". In: Trabalho e Crítica. São Leopoldo: Ed. UNISINOS, 2000.

GARDINER, P. Teorias da História. 3. a ed. Lisboa: Fundação Calouste Gulbenkian, 1984.

GEERTZ, C. A interpretação das culturas. Rio de Janeiro: LTC, 1989. (Antropologia Social, dir. G. Velho)

LORENZO, H. C.; COSTA, W. P. A década de 1920: as origens do Brasil moderno. S.Paulo: UNESP, 1997.

MAGALÃES, J. P. Da cadeira ao banco: Escola e modernização (Séculos XVIII ao XX). Lisboa: Educa, 2010.

MAGALHÃES, J. P. Contributo para a história das instituições educativas: entre a memória e o arquivo. In: FERNANDES, R.; MAGALHÃES, J. (orgs.). Para a história do ensino liceal em Portugal: Actas dos colóquios do I centenário da reforma de Jaime Moniz (1894 -1895). Braga, Portugal: Universidade do Minho, 1999.

MARTINS, A. O. Breve História da Obra Salesiana em Portugal. Lisboa: Edição Salesiana, 1942.

NÓVOA, A. Histoire et comparaison. Essais sur l'Éducation. Lisboa: Educa, 1998.

OLIVEIRA, A. X. O Padre Cícero que eu conheci: verdadeira história de Juazeiro do Norte. Rio de Janeiro: Olímpica, 1981.

OLIVEIRA, L. Centenário da presença Salesiana no Norte e Nordeste do Brasil: Salesiano cem anos, de 1933 a 1964. Recife: Escola Dom Bosco de Artes e Ofício, 1994.

OLIVEIRA, L.dos primórdios até 1932. Recife: Escola Dom Bosco de Artes e Ofícios, v. $1,1932$. 
PRADO, M. L. C. Repensando a história comparada da américa latina. São Paulo: FFLCH/USP. Revista de História, n. 153, p. 11-33, 2005.

RODRIGÉZ, J. Sabedoria do coração: Assistência salesiana. Trad. Claudia Maria Castro. 2. ed. São Paulo: Editora salesiana, 2003

SALESIANOS DE DOM BOSCO. Constituições e regulamentos. São Paulo: Escolas Profissionais Salesianas, 1985.

SILVA, A. A. Cartas do Padre Cícero: 1877-1934. Salvador, BA: Editora Salesiana, 1982.

SISTEMA EDUCATIVO NACIONAL DE PORTUGAL: 2003 / Ministério da Educação de Portugal y Organización de Estados Iberoamericanos.

TORRES, J. C. O. História das ideias religiosas no Brasil. São Paulo: Grijalbo, 1968.

\section{Como referenciar este artigo}

ALMEIDA, Núbia Ferreira. Formação profissional e cristã da juventude salesiana e a pedagogia de Dom Bosco. Revista Ibero-Americana de Estudos em Educação, Araraquara/SP, v. 11, n. esp. 3, p.1602-1615, 2016. Disponível em: <http://dx.doi.org/10.21723/riaee.v11.n.esp3.9078>. E-ISSN: 1982-5587.

Submetido em: agosto/2016

Aprovado em: novembro/2016 